\title{
China in action: national strategies to combat against emerging infectious diseases
}

\author{
Min $\operatorname{Han}^{1}$, Jinhui Gu², George F. Gao ${ }^{1,3}$ \& William J. Liu ${ }^{3 *}$ \\ ${ }^{1}$ CAS Key Laboratory of Pathogenic Microbiology and Immunology, Institute of Microbiology, Chinese Academy of Sciences, Beijing 100101, \\ China; \\ ${ }^{2}$ Division of Major Special Projects, Department of Health Science, Technology and Education at China's National Health and Family Planning \\ Commission, Beijing 100044, China; \\ ${ }^{3}$ National Institute for Viral Disease Control and Prevention, Chinese Center for Disease Control and Prevention, Beijing 102206, China
}

Received June 13,2017; accepted July 20,2017; published online September 7, 2017

Citation: $\quad$ Han, M., Gu, J., Gao, G.F., and Liu, W.J. (2017). China in action: national strategies to combat against emerging infectious diseases. Sci China Life Sci 60, 1383-1385. https://doi.org/10.1007/s11427-017-9141-3

During the 2013-2016 Ebola epidemic in West Africa, there was a special team as part of an international effort working in field. This was the Chinese aid team deployed to West Africa as a multidisciplinary group composed of experienced virologists, epidemiologists and physicians. As part of an international effort, they participated in the control of Ebola virus disease from the very beginning until the end of the outbreak, and currently retain a team in West Africa to prevent any subsequent flare-ups. Based out of a state-of-theart biosafety level III (BSL-3) lab in Sierra Leone, tens of thousands of suspected Ebola specimens were tested during the epidemic. This marked the first time that China has deployed public health specialists to countries outside of Asia to combat infectious disease outbreaks (Zhang and Gao, 2015; Gao and Feng, 2014).

Let us rewind to the situation in China during 2003. The outbreak of severe acute respiratory syndrome (SARS) at that time had wrought havoc on the society and economy of China, with over 7,000 infected cases in Hong Kong, Macau and mainland China combined. However, a potential positive is that this tragedy has highlighted the urgent need to control newly emerging and re-emerging infectious diseases, which

*Corresponding author (email: liujun@ivdc.chinacdc.cn) poses a great threat to human health (Yang et al., 2017). Since the conquer of SARS-CoV (Feng and Gao, 2007), prevention and emergency systems against infectious disease outbreaks in China have been greatly improved. To achieve these objectives, the Chinese government had devised a long-term plan and systematically implemented the details step-by-step. A large number of grants were provided with priority focus on funding infectious disease surveillance, basic research and the development of medical countermeasures, such as "The Control and Prevention of AIDS, Hepatitis and other Major Infectious Diseases" as one of the Major Special Projects for Science and Technology since 2008 , with over billions of yuan as cumulative funding thus far.

Through the implementation of these strategies, the largest network in the world for surveillance of a diverse spectrum of emerging pathogens was established. The network consists of over 800 laboratories with different hierarchical levels from national to provincial reference laboratories, as well as sentinel hospitals. Efforts involve the integration of rapid diagnostics in the clinic/laboratory and epidemiological investigations in the field, constituting a multi-faceted approach to limit the negative impacts of infectious disease outbreaks (Editorial, 2013). Early-warning, prevention of pathogen spread and prompt clinical treatment are the key 
characteristics of this coordinated, nation-wide disease control strategy in China. This is reflected through following two common features related to collaboration and innovation: (i) The surveillance system collected complementary data from different institutes/laboratories covering health, agriculture, military, universities and hospitals. (ii) The system is based on a three-tier system (national-provincial-municipal), covering all districts in China and allowing for the surveillance of pathogens with regional specificities.

This surveillance system has been used repeatedly in the years since to promptly combat outbreaks and/or imported cases of avian influenza virus (H1N1/H5N1/H5N6/H7N9), Zika virus, Yellow Fever virus, Rift Valley Fever virus, MERS-CoV, into China (Wang et al., 2015; Liu et al., 2017; Li et al., 2013; Chen et al., 2016a; Chen et al., 2016b). Over the past decade, the fight against infectious disease outbreaks in China has transitioned from a passive to a proactive approach, and these efforts have played a major role in ensuring that SARS-CoV outbreak of 2003-04 remains the last widespread epidemic in China to date. In particular, during the H7N9 avian influenza virus epidemic, different institutes under the Task Force of Joint Prevention and Control System responded well to the outbreak, drastically limiting the number of cases and deaths, and has been referred by the World Health Organization (WHO) as a model for the management of emerging diseases (Editorial, 2013).

Additionally, advances in basic research have been achieved in the rapid identification of novel emerging pathogens, characterization of the evolution, structural biology and development of vaccines/antimicrobials. This is evidenced by progress made with recent outbreaks of severe fever with thrombocytopenia syndrome virus (SFTSV), H7N9 influenza virus and Streptococcus suis in China (Li et al., 2013; Gao et al., 2013; Yu et al., 2011; Tang et al., 2006). Viruses with potential capability for interspecies transmission have been identified among wild animals, providing pivotal references for the early-warning of emerging pathogens (Shi et al, 2016; Huang et al., 2016). Other advances include the observation that H5N1 influenza virus is also lethal to wild migratory birds; contradicting a previously held belief these species are only the reservoir host of influenza viruses (Liu et al., 2005). In 2009, a vaccine against pandemic H1N1 influenza virus was developed within months (Zhu et al., 2009). The molecular basis of intra- and interspecies transmission for a number of highly pathogenic viruses including H5N1, H7N9, MERS-CoV and Ebola virus was clearly visualized through X-ray crystallography (Wang et al., 2016a; Lu et al., 2013; Shi et al., 2013; Zhang et al., 2013). Mechanisms of action with small molecular drugs/monoclonal antibodies against their specific viral targets have also been elucidated in the case of Zika or influenza (Wang et al., 2016b; Wu et al., 2015a; Wu et al., 2015b), allowing for the design of improved an- tiviral compounds in the future. During this process, the next generation of core talents and young scientists has gained valuable experience and hands-on training, ensuring efforts for the control and prevention against emerging infectious diseases can be sustained in the long term.

The progress made since 2003-2004 has not only allowed China to effectively combat infectious disease outbreaks within its own borders, but also to export their expertise and experiences during global public health crises. Fast-forwarding back to the 2013-2016 Ebola epidemic, hundreds of health care workers including physicians, epidemiologists and public health experts were deployed to West Africa to support diagnostic work, treatment of confirmed/suspect cases and provide training to local health specialists as well as education to the general population. Clinical trials for an adenovirus-vectored Ebola vaccine, developed by institutes from China, were carried out in mainland China as well as Sierra Leone (Zhu et al., 2017), and constitute one of the most promising Ebola vaccine candidates.

The Sierra Leone-China Friendship Biological Safety Laboratory was newly built in Jui, Freetown, with financial support from the Chinese government. This is the first and currently only state-of-the-art fixed BSL-3 laboratory in West Africa (Liu, 2016). In recognition of the contributions made by the laboratory, the Ministry of Health and Sanitation of Sierra Leone designated the laboratory in June 2016 as the "National Reference Laboratory for Viral Hemorrhagic Fevers" and the "National Training Center for Virus Detection and Biosafety". Currently, the Chinese Center for Diseases Control and Prevention (China CDC) team collaborates with local specialists to perform routine laboratory testing and scientific research on any circulating infectious diseases in Sierra Leone.

New techniques based on the most recent innovations to control and prevent emerging infectious diseases will be continuously incorporated into the surveillance system, strengthening the development of new techniques on pathogen identification, surveillance and early-warning, emergency vaccine development/clinical treatment, and animal models for testing of medical countermeasures. The objective is to control any outbreaks during the initial stages using multiple approaches, thereby minimizing the impact on the economy and social development. The implementation and success of these strategies in China provides a refreshing and alternative reference for the global collaborative efforts against public health crises.

Compliance and ethics The author(s) declare that they have no conflict of interest.

Acknowledgements We thank Dr. Gary Wong for critical review of the manuscript. This work was supported by Major Special Projects for Infectious Disease Research of China (2016ZX10004222-003), National Natural 
Science Foundation of China $(81401312,81373141)$, and the National Natural Science Foundation of China (81321063 to George F. Gao).

Chen, H., Liu, S., Liu, J., Chai, C., Mao, H., Yu, Z., Tang, Y., Zhu, G., Chen, H.X., Zhu, C., Shao, H., Tan, S., Wang, Q., Bi, Y., Zou, Z., Liu, G., Jin, T., Jiang, C., Gao, G.F., Peiris, M., Yu, H., and Chen, E. (2016a). Nosocomial co-transmission of avian influenza A(H7N9) and A(H1N1)pdm09 viruses between 2 patients with hematologic disorders. Emerg Infect Dis 22, 598-607.

Chen, Z., Liu, L., Lv, Y., Zhang, W., Li, J., Zhang, Y., Di, T., Zhang, S., Liu, J., Li, J., Qu, J., Hua, W., Li, C., Wang, P., Zhang, Q., Xu, Y., Jiang, R., Wang, Q., Chen, L., Wang, S., Pang, X., Liang, M., Ma, X., Li, X., Wang, Q., Zhang, F., and Li, D. (2016b). A fatal yellow fever virus infection in china: description and lessons. Emerg Microbes Infect 5, e69.

Editorial. (2013). The fight against bird flu. Nature 496, 397.

Feng, Y., and Gao, G.F. (2007). Towards our understanding of SARS-CoV, an emerging and devastating but quickly conquered virus. Compar Immunol Microbiol Infect Dis 30, 309-327.

Gao, G.F., and Feng, Y. (2014). On the ground in Sierra Leone. Science 346, 666-666.

Gao, R., Cao, B., Hu, Y., Feng, Z., Wang, D., Hu, W., Chen, J., Jie, Z., Qiu, H., Xu, K., Xu, X., Lu, H., Zhu, W., Gao, Z., Xiang, N., Shen, Y., He, Z., Gu, Y., Zhang, Z., Yang, Y., Zhao, X., Zhou, L., Li, X., Zou, S., Zhang, Y., Li, X., Yang, L., Guo, J., Dong, J., Li, Q., Dong, L., Zhu, Y., Bai, T., Wang, S., Hao, P., Yang, W., Zhang, Y., Han, J., Yu, H., Li, D., Gao, G.F., Wu, G., Wang, Y., Yuan, Z., and Shu, Y. (2013). Human infection with a novel avian-origin influenza A (H7N9) Virus. N Engl J Med 368, 1888-1897.

Huang, C., Liu, W.J., Xu, W., Jin, T., Zhao, Y., Song, J., Shi, Y., Ji, W., Jia, H., Zhou, Y., Wen, H., Zhao, H., Liu, H., Li, H., Wang, Q., Wu, Y., Wang, L., Liu, D., Liu, G., Yu, H., Holmes, E.C., Lu, L., and Gao, G.F. (2016). A bat-derived putative cross-family recombinant coronavirus with a Reovirus gene. PLoS Pathog 12, e1005883.

Li, J., Yu, X.F., Pu, X.Y., Xie, L., Sun, Y.X., Xiao, H.X., Wang, F.J., Din, H., Wu, Y., Liu, D., Zhao, G.Q., Liu, J., and Pan, J.C. (2013). Environmental connections of novel avian-origin H7N9 influenza virus infection and virus adaptation to the human. Sci China Life Sci 56, 485-492.

Liu, J., Sun, Y., Shi, W., Tan, S., Pan, Y., Cui, S., Zhang, Q., Dou, X., Lv, Y., Li, X., Li, X., Chen, L., Quan, C., Wang, Q., Zhao, Y., Lv, Q., Hua, W., Zeng, H., Chen, Z., Xiong, H., Jiang, C., Pang, X., Zhang, F., Liang, M., Wu, G., Gao, G.F., Liu, W.J., Li, A., and Wang, Q. (2017). The first imported case of Rift Valley fever in China reveals a genetic reassortment of different viral lineages. Emerg Microbes Infect 6, e4.

Liu, J., Xiao, H., Lei, F., Zhu, Q., Qin, K., Zhang, X.W., Zhang, X.L., Zhao, D., Wang, G., Feng, Y., Ma, J., Liu, W., Wang, J., and Gao, G.F. (2005). Highly pathogenic $\mathrm{H} 5 \mathrm{~N} 1$ influenza virus infection in migratory birds. Science 309, 1206-1206.

Liu, W.J. (2016). On the ground in Western Africa: from the outbreak to the elapse of Ebola. Protein Cell 7, 621-623.

Lu, G., Hu, Y., Wang, Q., Qi, J., Gao, F., Li, Y., Zhang, Y., Zhang, W., Yuan, Y., Bao, J., Zhang, B., Shi, Y., Yan, J., and Gao, G.F. (2013). Molecular basis of binding between novel human coronavirus MERS-CoV and its receptor CD26. Nature 500, 227-231.

Shi, M., Lin, X.D., Tian, J.H., Chen, L.J., Chen, X., Li, C.X., Qin, X.C., Li, J., Cao, J.P., Eden, J.S., Buchmann, J., Wang, W., Xu, J., Holmes, E.C., and Zhang, Y.Z. (2016). Redefining the invertebrate RNA virosphere. Nature 540, 539-543.

Shi, Y., Zhang, W., Wang, F., Qi, J., Wu, Y., Song, H., Gao, F., Bi, Y., Zhang, Y., Fan, Z., Qin, C., Sun, H., Liu, J., Haywood, J., Liu, W., Gong, W., Wang, D., Shu, Y., Wang, Y., Yan, J., and Gao, G.F. (2013). Structures and receptor binding of hemagglutinins from human-infecting H7N9 influenza viruses. Science 342, 243-247.
Tang, J., Wang, C., Feng, Y., Yang, W., Song, H., Chen, Z., Yu, H., Pan, X., Zhou, X., Wang, H., Wu, B., Wang, H., Zhao, H., Lin, Y., Yue, J., Wu, Z., He, X., Gao, F., Khan, A.H., Wang, J., Zhao, G.P., Wang, Y., Wang, X., Chen, Z., and Gao, G.F. (2006). Streptococcal toxic shock syndrome caused by Streptococcus suis serotype 2. PLoS Med 3, e151.

Wang, H., Shi, Y., Song, J., Qi, J., Lu, G., Yan, J., and Gao, G.F. (2016a). Ebola viral glycoprotein bound to its endosomal receptor Niemann-pick C1. Cell 164, 258-268.

Wang, Q., Yang, H., Liu, X., Dai, L., Ma, T., Qi, J., Wong, G., Peng, R., Liu, S., Li, J., Li, S., Song, J., Liu, J., He, J., Yuan, H., Xiong, Y., Liao, Y., Li, J., Yang, J., Tong, Z., Griffin, B.D., Bi, Y., Liang, M., Xu, X., Qin, C., Cheng, G., Zhang, X., Wang, P., Qiu, X., Kobinger, G., Shi, Y., Yan, J., and Gao, G.F. (2016b). Molecular determinants of human neutralizing antibodies isolated from a patient infected with Zika virus. Sci Transl Med 8, 369ra179-369ra179.

Wang, Y., Liu, D., Shi, W., Lu, R., Wang, W., Zhao, Y., Deng, Y., Zhou, W., Ren, H., Wu, J., Wang, Y., Wu, G., Gao, G.F., and Tan, W. (2015). Origin and possible genetic recombination of the middle east respiratory syndrome coronavirus from the first imported case in china: phylogenetics and coalescence analysis. MBio 6, e01280-15.

Wu, Y., Cho, M.S., Shore, D., Song, M., Choi, J.A., Jiang, T., Deng, Y.Q., Bourgeois, M., Almli, L., Yang, H., Chen, L.M., Shi, Y., Qi, J., Li, A., Yi, K.S., Chang, M.S., Bae, J.S., Lee, H.J., Shin, J.Y., Stevens, J., Hong, S.S., Qin, C.F., Gao, G.F., Chang, S.J., and Donis, R.O. (2015a). A potent broad-spectrum protective human monoclonal antibody crosslinking two haemagglutinin monomers of influenza A virus. Nat Commun 6, 7708.

Wu, Y., Vavricka, C.J., Wu, Y., Li, Q., Rudrawar, S., Thomson, R.J., von Itzstein, M., Gao, G.F., and Qi, J. (2015b). Atypical group 1 neuraminidase pH1N1-N1 bound to a group 1 inhibitor. Protein Cell 6, 771-773.

Yang, S., Wu, J., Ding, C., Cui, Y., Zhou, Y., Li, Y., Deng, M., Wang, C., Xu, K., Ren, J., Ruan, B., and Li, L. (2017). Epidemiological features of and changes in incidence of infectious diseases in China in the first decade after the SARS outbreak: an observational trend study. Lancet Infect Dis 17, 716-725.

Yu, X.J., Liang, M.F., Zhang, S.Y., Liu, Y., Li, J.D., Sun, Y.L., Zhang, L., Zhang, Q.F., Popov, V.L., Li, C., Qu, J., Li, Q., Zhang, Y.P., Hai, R., Wu, W., Wang, Q., Zhan, F.X., Wang, X.J., Kan, B., Wang, S.W., Wan, K.L., Jing, H.Q., Lu, J.X., Yin, W.W., Zhou, H., Guan, X.H., Liu, J.F., Bi, Z.Q., Liu, G.H., Ren, J., Wang, H., Zhao, Z., Song, J.D., He, J.R., Wan, T., Zhang, J.S., Fu, X.P., Sun, L.N., Dong, X.P., Feng, Z.J., Yang, W.Z., Hong, T., Zhang, Y., Walker, D.H., Wang, Y., and Li, D.X. (2011). Fever with thrombocytopenia associated with a novel Bunyavirus in China. N Engl J Med 364, 1523-1532.

Zhang, B.K., and Gao, G.F. (2015). A new chapter for China's public health security—aids offered to Africa to combat Ebola. Sci China Life Sci 58, 114-116.

Zhang, W., Shi, Y., Lu, X., Shu, Y., Qi, J., and Gao, G.F. (2013). An airborne transmissible avian influenza $\mathrm{H} 5$ hemagglutinin seen at the atomic level. Science 340, 1463-1467.

Zhu, F.C., Wang, H., Fang, H.H., Yang, J.G., Lin, X.J., Liang, X.F., Zhang, X.F., Pan, H.X., Meng, F.Y., Hu, Y.M., Liu, W.D., Li, C.G., Li, W., Zhang, X., Hu, J.M., Peng, W.B., Yang, B.P., Xi, P., Wang, H.Q., and Zheng, J.S. (2009). A novel influenza A (H1N1) vaccine in various age groups. N Engl J Med 361, 2414-2423.

Zhu, F.C., Wurie, A.H., Hou, L.H., Liang, Q., Li, Y.H., Russell, J.B.W., Wu, S.P., Li, J.X., Hu, Y.M., Guo, Q., Xu, W.B., Wurie, A.R., Wang, W.J., Zhang, Z., Yin, W.J., Ghazzawi, M., Zhang, X., Duan, L., Wang, J.Z., and Chen, W. (2017). Safety and immunogenicity of a recombinant adenovirus type- 5 vector-based Ebola vaccine in healthy adults in Sierra Leone: a single-centre, randomised, double-blind, placebo-controlled, phase 2 trial. Lancet 389, 621-628. 